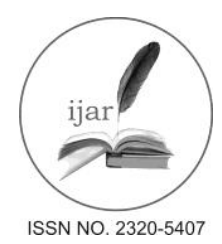

Journal homepage: http://www.journalijar.com
Journal DOI: 10.21474/IJAR01

INTERNATIONAL JOURNAL

OF ADVANCED RESEARCH

RESEARCH ARTICLE

\title{
SOLAR POWERED AIR CONDITIONING SYSTEM FOR LMV.
}

Anuja.r.jadhav ${ }^{1}$ and mr.a.d.bhoi ${ }^{2}$.

1. Student, G.H Raisoni institute of engineering and technology wagholi-pune, India.

2. Faculty, G.H Raisoni institute of engineering and technology wagholi-pune, India.

\section{Manuscript Info}

\section{Manuscript History:}

Received: 25 April 2016

Final Accepted: 19 May 2016

Published Online: June 2016

Key words:

Solar panel, Power supply, AC

cooler, PIC 16f877A microcontroller,

Battery, LCD display.

*Corresponding Author

Anuja.r.jadhav.

\section{Abstract}

Today many vehicles are run on the non renewable sources like petrol, diesel etc so there is increase in environmental pollution in the world. The major problem is green house effect caused due to the fossil fuel which introduce the $\mathrm{CO} 2$ will cause lots of problem. Therefore reducing the environmental pollution there are many renewable sources such as solar energy, Wind energy, Tidal energy etc. Solar energy is a renewable source. Now-a-days solar energy is used to produce the electricity from the sun.

Solar powered system has an advantage that it doesn't required a gas and solves the many problem related to the environment. In this system uses solar panel to turn on the air condition system. In summer days the keeps the air conditioning system is on even the engine is switched off.

The objectives of the system are that optimal utilization of the solar energy for LMV, find out the performance of the system and analyze the performance of the system.

Copy Right, IJAR, 2016,. All rights reserved.

\section{Introduction:-}

In recent decades demand for vehicles are increased that caused the environmental pollution in the whole world. The fossil fuel such as petrol and diesel are very expensive. The use of fossil fuel based vehicle causes the air pollution which is very harmful for the human body. Transportation of this fossil fuel to rural area is a big problem. The major problem is green house effect cased due to the fossil fuel which introduce the CO2 will cause lots of problem. Therefore reducing the pollution there were many renewable sources are used like solar energy, Wind energy, Tidal energy etc.

One of the greatest energy sources is the sun energy. Solar system can be classified into two categories; those are thermal system which converts solar energy to thermal energy and photovoltaic system which converts solar energy to electrical energy. In the last two centuries, solar energy is used to generate the electricity from the sun. In 1839 Alexander Edmond discovered the photovoltaic effect which explains how electricity can be generated from sunlight. In 1941, Russell Ohl invented the first solar cell after the invention of transistor. Solar energy is the renewable source and freely available in the market. Solar energy provides the power to the air conditioning system for vehicle. Solar vehicle depends on photo voltaic (PV) cell to convert sunlight into electricity and given to the air conditioning system for the vehicle. PV cell directly convert sunlight into electricity. Solar panels can generate electricity without any waste or pollution. Solar panels are relatively easy to install and very low maintenance. To achieving the required voltage, PV cells are connected in either series or parallel thus is make cost effective.

Different researchers studied on solar powered Air Conditioning system as an innovative technology for reducing the pollution and save the electricity. Balamurugan.T and Manoharan. S introduced that an implementation of Solar/Electric/Reduced fuel consumption (IC Engine) Hybrid Powered Vehicle (SEFPHV) technology which is the 
combination of multi sources. The vehicles will run with the help of solar power, electric power and less amount of fuel [1].

"A Solar-powered Battery Charger with Neural Network Maximum Power Point Tracking Implemented on a LowCost PIC-microcontroller" in this paper author introduced implementation of maximum power point tracking algorithm (MPPT). Using MPPT algorithm solar powered battery charging system has been successfully implemented on low cost PIc16F877 RISC microcontroller 2]. Victor Del Razo, Hans-Arno Jacobsen ""VehicleOriginating-Signals for Real-Time Charging Control of Electric Vehicle Fleets" introduced charging the electric vehicle in electricity distribution network. The goal is to manage the power consumption including solar generation [3].

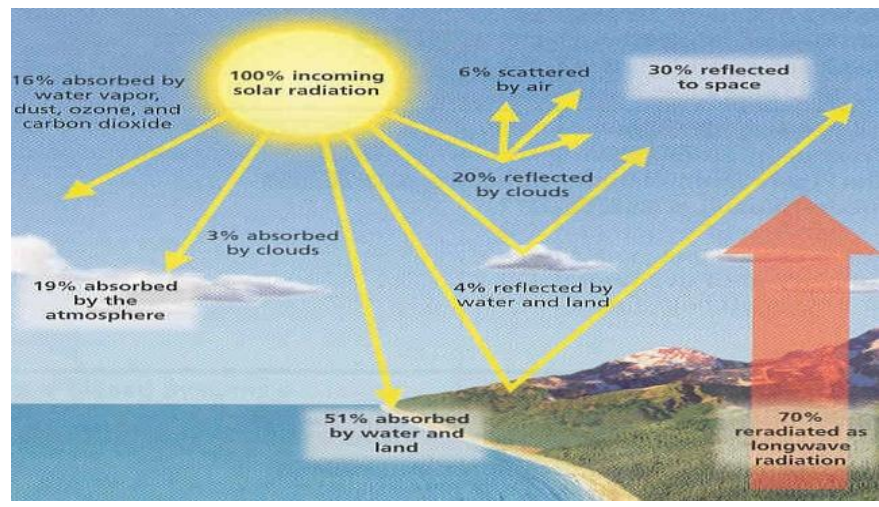

Fig1:- Distribution of Solar Energy.

Above fig 1 shows the distribution of solar energy. Sun energy is the greatest energy in the world. Sun energy is the natural energy which is easily available in free of cost. In fig1 how the sun energy distributed over the different parts such as sun energy is absorbed by water, land, clouds and air. Air conditioning system is a system used for cooling and dehumidifying air. The basic components of car AC are compressor, condenser, receiver dryer and evaporator. Following fig 2 shows the solar powered car.

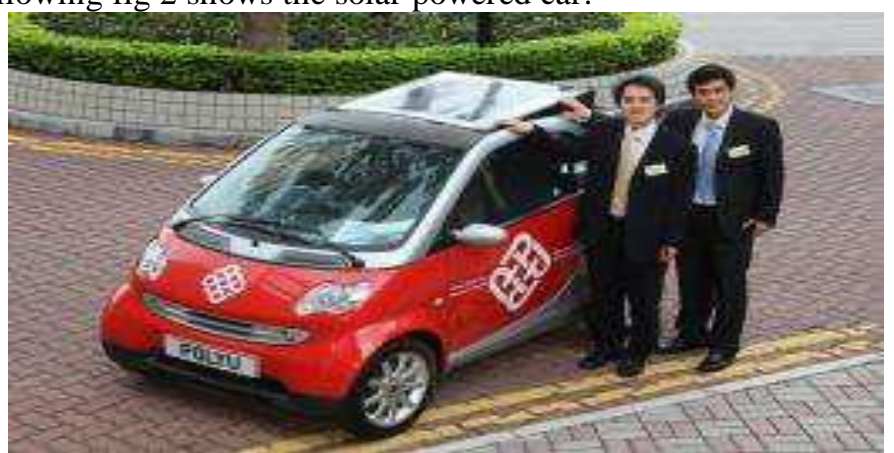

Fig2:- Solar Powered Car.

The objective is the optimal utilization of sun energy source for vehicle and increase the performance of the system.

\section{Need:-}

Today increasing demand for highly automatic \& luxurious cars, there is increase in environmental pollution throughout the world. Due to the increasing the pollution in the environment causes the greenhouse effect, reducing the ozone layer, increasing $\mathrm{CO} 2$ in the air. The most important function is to reduce the air pollution by using different energy sources such as solar energy, wind energy, Tidal energy are used.

The most important function is to reduce the air pollution by using solar generation. Solar energy is the renewable energy source. The need is continue to keep the air conditioning system on during the hot sunny days even when the engine is switched off. Solar panel is made of a flexible material so that it placed on the roof of the car and it charges the battery which turns the air condition system. 


\section{Methodology:- \\ Proposed Design:-}

Design of solar powered air conditioning system for LMV system mainly consists of following blocks are Power supply, Microcontroller PIC16F877A, 2 Solar panels, 16X2 LCD, battery, mobile charger unit and A.C.

\section{Hardware and Software Requirement:-}

\section{Power supply.}

2. PIC16F877A Microcontroller.

3. Liquid Crystal Display (LCD).

4. Battery.

5. AC fan.

6. Solar Panel.

7. Boost Convertor.

8. Micro $\mathrm{C}$ for PIC Programming.

9. PIC kit2 IC burning.

10. MATLAB.

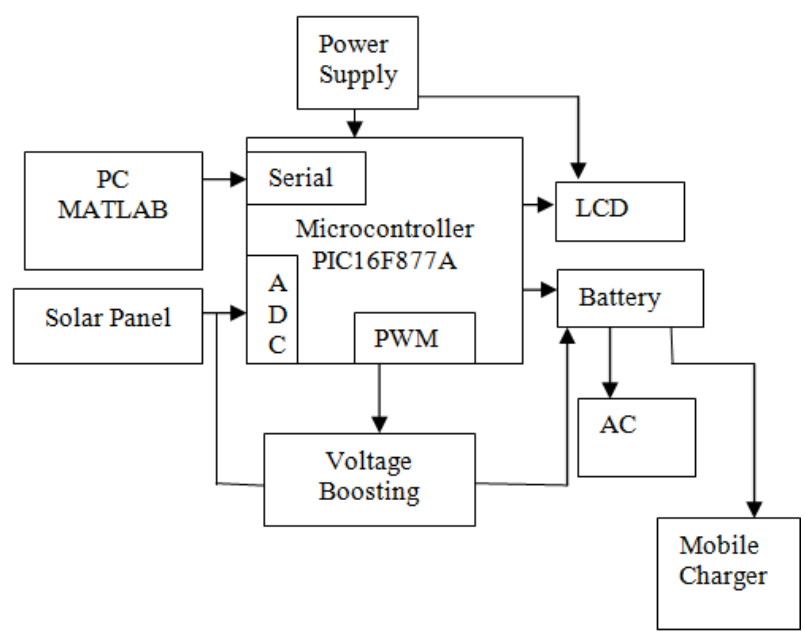

Fig 3:- Block diagram of Solar powered Air Conditioning System for LMV.

\section{Description:-}

The project consists of various units viz., power supply, Microcontroller PIC16F877A, 2 Solar panels, 16X2 LCD, battery, mobile charger unit and A.C. Solar panel with power is 45 watt will be used. The voltage will be monitored through PIC microcontroller using Analog to Digital channel. Corresponding voltage value will be display on the LCD interfaced with microcontroller. The same supply from solar panels will be given to 12 Volt batteries which are supplying power to Air conditioning system and mobile charger unit. Also, battery voltage will be monitored continuously through another Analog to Digital channel of microcontroller. Current and voltage of battery will be monitored continuously through signal conditioning unit.

The voltage values of battery will be sent to PC serially out. Graphical User Interface (GUI) is created on MATLAB to show graphical representation of voltage values. The data can be stored in text format using GUI.

In above fig3 consists of different units such as power supply, Microcontroller PIC16F877A, 2 Solar panels, 16X2 LCD, battery, mobile charger unit and A.C. Explanation of each unit is as below,

\section{Principle of Operation:-}

Solar Panel:-

Solar panel is used to convert the solar energy to electrical energy. Using photovoltaic cell, energy from the sun can be converted into electricity that we can use every day. Silicon is one of the materials used in photovoltaic cell to convert sun's energy into electricity. The sun is a great natural resource of energy. On a sunny day, the sun provides approximately 1000 watts of power per. from heating water for steam turbines to directly generating electricity through photovoltaic devices. This paper focuses on solar energy by means of photovoltaic devices. 
Specification of solar panel

\begin{tabular}{|c|c|}
\hline Number of solar panel & 1 \\
\hline Number of cell & 60 \\
\hline Material & Silicon, aluminium \\
\hline Solar Power & 45 Watt \\
\hline Solar voltage & $12 \mathrm{~V}$ \\
\hline Solar current & $4 \mathrm{~A}$ \\
\hline Weight & $4.5 \mathrm{~kg}$ \\
\hline
\end{tabular}

panel is used to convert the solar energy to electrical energy. Using photovoltaic cell, energy from the sun can be converted into electricity that we can use every day. Silicon is one of the materials used in photovoltaic cell to convert sun's energy into electricity

\section{Battery:-}

Battery is source of electrical energy. These are the devices, which maintain current by transferring chemical energy into electrical energy. The essential difference between a cell and a battery is that the cell is a single unit, which converts chemical energy into electrical energy whereas battery is a combination of these cells.

Specification of Battery

\begin{tabular}{|c|c|}
\hline Voltage rating & $12 \mathrm{~V}$ \\
\hline Battery capacity & $8.2 \mathrm{AH}$ \\
\hline Max charging current & $2.28 \mathrm{~A}$ \\
\hline Fastest possible charging time & $4 \mathrm{Hr}$ \\
\hline Do not charge battery faster than & $2.8 \mathrm{~A}$ \\
\hline
\end{tabular}

\section{Microcontroller PIC 16F877A:-}

PIC is the family of Harvard architecture microcontroller made by microchip technology. PIC is popular with industrial developers because of low cost, wild availability. Voltage will be monitored through PIC microcontroller using analog to digital convertor.

\section{Features:-}

Special Microcontroller Features:

* 100,000 erase/write cycle Enhanced Flash program memory typical.

* 1,000,000 erase/write cycle Data EEPROM memory typical.

* Self-reprogrammable under software control.

* In-Circuit Serial Programming ${ }^{\text {TM }}$ (ICSPTM) via two pins.

* Single-supply 5V In-Circuit Serial Programming.

* Watchdog Timer (WDT) with its own on-chip RC oscillator for reliable operation.

\section{Analog Features:-}

* 10-bit, up to 8-channel Analog-to-Digital Converter (A/D).

* Brown-out Reset (BOR).

* Analog Comparator module with:

- Two analog comparators.

- $\quad$ Programmable on-chip voltage reference (VREF) module.

- Programmable input multiplexing from device inputs and internal voltage reference.

- Comparator outputs are externally accessible.

Peripheral Features:

* Timer0: 8-bit timer/counter with 8-bit pre scalar

* Timer1:16-bit timer/counter with pre scalar.

* Timer2: 8-bit timer/counter with 8-bit period register, pre scalar and post scalar

* Two Capture, Compare, PWM modules

- Capture is 16-bit, max. Resolution is $12.5 \mathrm{~ns}$

- Compare is 16-bit, max. Resolution is $200 \mathrm{~ns}$

- PWM max. Resolution is 10-bit 
* Synchronous Serial Port (SSP)

* Universal Synchronous Asynchronous Receiver Transmitter (USART/SCI) with 9-bit address detection.

\section{Liquid Crystal Display:-}

A liquid crystal dot matrix display module consists of LCD panel, LCD control driver and providing 16 character $\mathrm{x}$ 2 lines display. It contains a controller, a data RAM, character generator ROM required for providing display. Data interfacing is in 8-bit parallel or 4-bit parallel and data can be written in or read from a microprocessor. Liquid Crystal Display has 16 pins in which first three and 15th pins are used for power supply. 4th pin is RS (Register Selection) if it is low data and if it is high command will be displayed. 5th pin is $\mathrm{R} / \mathrm{W}$ if it is low it performs write operation. 6th pin act as enable and remaining pins are data lines. The LCD displays the corresponding voltage which is interfaced with the microcontroller.

\section{Air Conditioning System:-}

AC defines "The process of controlling temperature, humidity and cleanliness. It consists of different parts such as, Compressor, Condenser, and Evaporator. The function of compressor is to compress the gas coming from the evaporator. The compressor of the car generates compressed gas and sends it to the condenser, where the gas begins to cool. The function of the evaporator is to absorb the heat which is present in the car. The evaporator contains cold Freon gas. This gas passes through the evaporator and makes evaporator very cold.

AC fan Specification

\begin{tabular}{|c|c|}
\hline Voltage rating & $12 \mathrm{~V}$ \\
\hline Power rating & $20 \mathrm{~W}$ \\
\hline Current rating & $1.6 \mathrm{~A}$ \\
\hline
\end{tabular}

\section{Boost Convertor:-}

Boost converter is a DC-to-DC power converter steps up voltage (while stepping down current) from its input (supply) to its output (load). To reduce voltage ripple, normally added to such a converter's output (load-side filter) and input (supply-side filter). Power for the boost converter can come from any suitable DC sources, such as batteries, solar panels, rectifiers and DC generators. A boost converter is a DC to DC converter with an output voltage greater than the source voltage. A boost converter is sometimes called a step-up converter. Boost converters can increase the voltage and reduce the number of cells.

\section{Software flowchart:-}

MATLAB software is mainly used for coding. Fig4 shows software flowchart of proposed system. It consist of following steps

1. Start

2. Initialize the microcontroller, LCD, PWA, ADC, Serial

3. Read output of solar panel at ADC channel.

4. Display the voltage on LCD \& given PWM signal to boost convertor.

5. Ac is on \& mobile charger is on.

6. When output of solar at ADC will be read then voltage will be display on LCD

7. Send data serially to PC, Run GUI.

8. Read serial port at AC.

9. Read voltage value, plot voltage on axis, write a text

10. Stop. 


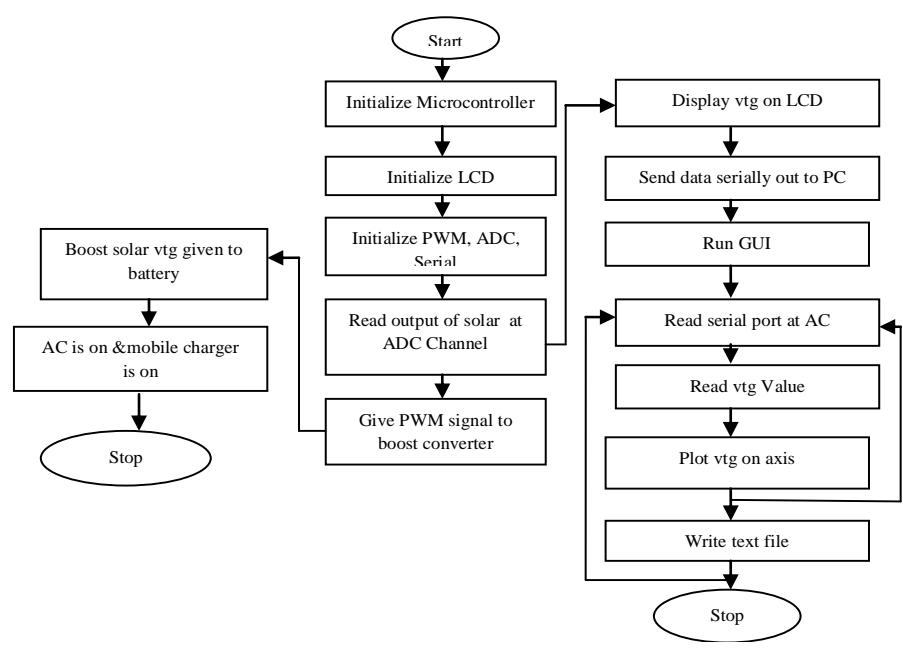

Fig 5:- Software flowchart of the System.

\section{Result:-}

As per the flow chart is working. Output of the solar panel is read by ADC and voltage is display on the LCD. PWM signal given to the boost convertor and its voltage is given to battery. After that we run the AC as well as mobile is charged. For getting the solar voltage waveform, MATLAB is used. Solar output is serially sent to the PC and run the GUI (Graphical user interface).Read this voltage value, plot the axis and write a text file.

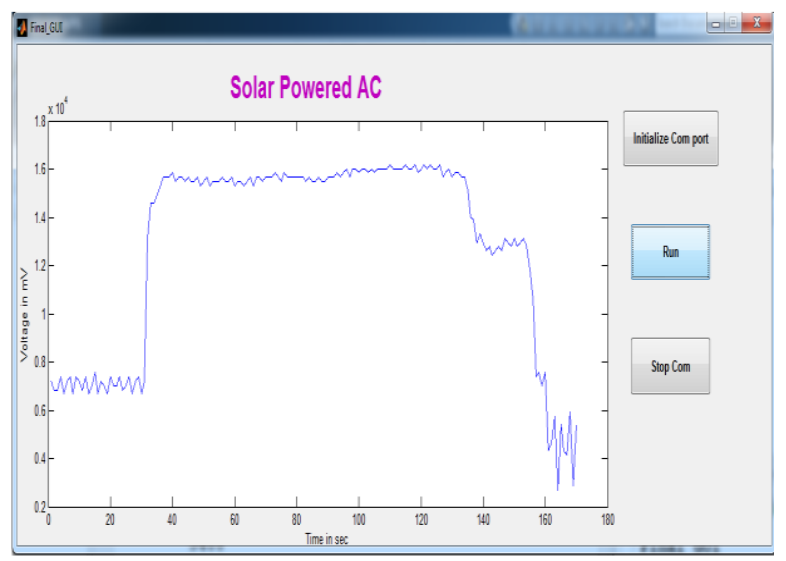

Fig 6:- Output of MATLAB code calculating variable voltage of solar.

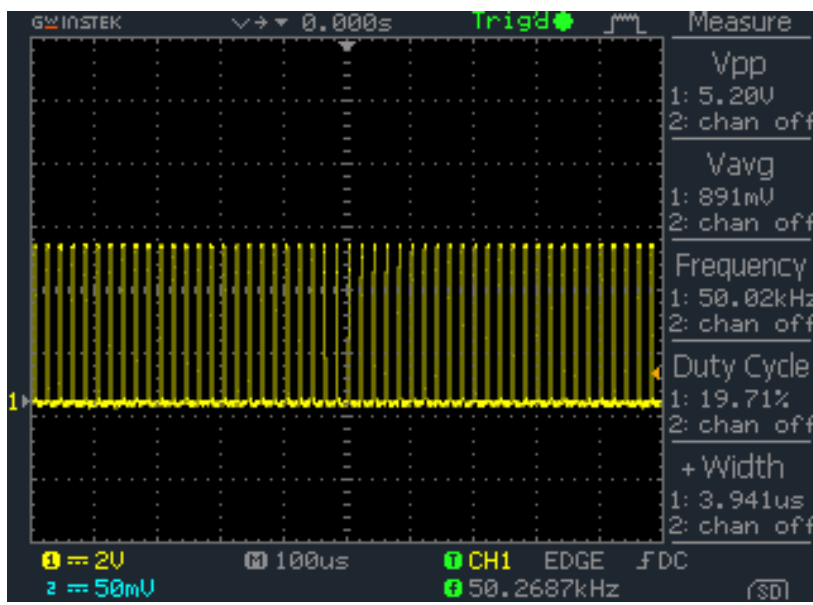

Fig7:- PWM frequency initialized at $50 \mathrm{KHz} 18 \%$ duty cycle. 


\section{Conclusion:-}

As discuss above, it is observed that the energy and water are the basic need for us to live a normal life. Solar energy technology and its uses are very important for developing countries. It's also reducing the greenhouse effect. Solar energy is the renewable energy. It saves the nonrenewable sources such as petrol, diesel.

The main motivation of the solar energy is to reduce the pollution and saves the electricity. Solar energy is ecofriendly energy. The solar cooling reduces the cost of air conditioning compare to normal AC. Solar cooling is the good example for changing the climate.

\section{Acknowledgment:-}

Author is extremely thankful to research to research guide "Mr.A.D.Bhoi", G. H. Raisoni institute of engineering and technology, Pune for consistent guidance, inspiration and his valuable support.

I am also grateful to our college principal- "Prof.Dr.R.D.kharadkar" and HOD of electronics\& telecommunication department "Prof.N.B. Hulle" for their valuable support and guidance.

\section{References:-}

1. Balamurugan.T, Manoharan. S, "Optimal Design and Control of Solar/Electric/Reduced fuel consumption(IC engine) Hybrid Powered Vehicle (SEFPHV) Technology", International Journal of Renewable Energy Technology Research Vol. 2, No. 5, May 2013, PP: 151 - 169, ISSN: 2325-3924 (Online) Available online www.ijretr.org

2. Panom PetchjatupornI,Wannaya NgamkhamI"A Solar-powered Battery Charger with Neural Network Maximum Power Point Tracking Implemented on a Low-Cost PIC-microcontroller",2394-525-778-185-8 IEEE 2012.

3. Victor del Razo, Hans-Arno Jacobsen, "Vehicle-Originating-Signals for Real-Time Charging Control of Electric Vehicle Fleets", IEEE Transactions On Transportation Electrification, Vol. 1, No. 2, August 2015.

4. V Mittal,KS Kasana,NS Thakur, " The study of solar absorption air-conditioning systems", Journal of Energy in Southern Africa Vol 16 No 4 November 2005.

5. Khaled S. Al Qdah"Performance of Solar-Powered Air Conditioning System under AlMadinah AlMunawwarah Climatic Conditions",Smart Grid and Renewable Energy, 2015, 6, 209-219.

6. Shivani Jain, Neha Tiwari"Grid Solar Hybrid Speed Controller for Electric Vehicle - A Working Model",International Journal of Scientific Engineering and Research (IJSER) ISSN (Online): 2347-3878 Volume 3 Issue 1, January 2015.

7. Ke Bao, Shuhui Li and Huiying Zheng, " Battery Charge and Discharge Control for Energy Management in EV and Utility Integration" ,2012 IEEE.

8. Alisaa Kumari, Ankita Ranjan, Shivangi Srivastava"Solar Powered Vehicle",International Journal of Electronics, Electrical and Computational System IJEECS ISSN 2348-117X Volume 3, Issue 3 May 2014.

9. Rony Sorkar, Zubaear Alam \& Galib Hashmi"Design and Development of a Low Cost Solar Automated Vehicle",Global Journal of Researches in Engineering: F Electrical and Electronics Engineering Volume 15 Issue 6 Version 1.0 Year 2015.

10. Wilfred Lai," Solar-powered air-conditioning system for vehicles", 11 October 2011. 